\title{
Gastrite em suínos: freqüência, relação com a úlcera gástrica e com a densidade de células endócrinas do estômago
}

\section{Swine gastritis: frequency, relationship with gastric ulcer and with the density of stomach endocrine cells}

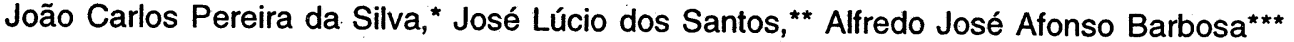

\section{Resumo}

Este trabalho teve como objetivos conhecer a freqüência de gastrite em suínos, bem como verificar a eventual relação entre essa patologia e úlcera gástrica e a influência da gastrite sobre a gastrinemia e sobre a densidade de células endócrinas da mucosa gástrica. Para tal foram utilizados 64 suínos adultos, divididos em dois grupos: com e sem úlcera gástrica. A dosagem de gastrina foi realizada através de radioimunoensaio, enquanto a identificação das células endócrinas se fez por meio de técnicas histoquímicas (Grimelius e Masson-Fontana modificada) e imunocitoquímica (PAP). Os resultados demonstraram que o processo inflamatório gástrico é mais freqüente na mucosa cárdica, seguida da antral e finalmente na mucosa oxíntica. Verificou-se também que a presença de gastrite não alterou a densidade de células endócrinas e a gastrinemia em suínos. Foi ainda observada a inexistência de associação entre gastrite e úlcera gástrica.

Palavras-chave: gastrite; úlcera gástrica; células endócrinas; gastrina; suíno.

\begin{abstract}
This work had as objective knowing the frequency of gastritis in swines, as well as verifying the influence of the gastritis on the gastrinaemia and the density of endocrine cells of the gastric mucosa. For such 64 adult swines had been used, divided in two groups: with and without gastric ulcer. The nivels of gastrin was carried through radioimmunoassay, while the identification of the endocrine cells had been made by means of histochemical techniques (Grimelius and modified Masson-Fontana) and immunocitochemistry (PAP). The results had demonstrated that the gastric inflammatory process is more frequent in the cardiac mucosa, followed of the antral and finally in the oxyntic mucosa. It was also verified that the gastritis presence did not modify the density of endocrine cells and the gastrinaemia in swines. It has been observing the inexistence of association between gastritis and gastric ulcer.
\end{abstract}

Keywords: gastritis; gastric ulcer; endocrine cells; gastrin; swine.

\section{Introdução}

Gastrite é o processo inflamatório da mucosa gástrica acompanhada não somente por alterações histológicas e imunológicas, mas também por perturbações da secreção endócrina. Na literatura médica, vários trabalhos têm enfatizado a importância da gastrite como entidade patológica, associando-a com importantes distúrbios gastrintestinais, sobretudo com a úlcera péptica (Graham, 1989). Da mesma forma, outras publicações estabeleceram relações entre a gastrite e alterações da homeostase gástrica, em especial com a densidade de células endócrinas da mucosa do estômago (Rubin, 1969; Creutzfeldt et al., 1985) e com alterações da gastrinemia (Borch et al., 1986).

Por outro lado, nos animais domésticos a gastrite, como entidade mórbida, raramente tem sido descrita. Isso poderia ser atribuída à sua baixa frequência, ou à sua reduzida importância clínico-patológica, e/ou econômica. Similarmente ao que acontece em medicina humana, nos últimos anos, vários trabalhos têm demonstrado uma relação positiva entre a presença de bactérias espiraladas e a presença de gastrite. em suínos (Bertram et al., 1991; Mendes et al., 1991; Grasso et al., 1996). Apesar da alta freqüência da úlcera gástrica na espécie suína, que em alguns rebanhos ultrapassa a $30 \%$, a ocorrência de gastrite e sua eventual relação com a úlcera da pars oesophagea e com distúrbios da homeostase endócrina gastrintestinal ainda não foram estabelecidas nessa espécie animal.

Visando estabelecer parâmetros para a histologia ou patologia comparadas, realizou-se o presente trabalho, que teve como objetivos: conhecer a freqüência de processos inflamatórios nas diferentes regiões glandulares do estômago, \footnotetext{
*Médico Veterinário-Doutor-Professor titular do Departamento de Veterinária da UFV - Viçosa, MG - CEP 36571-000. Autor para correspondência.
E-mail:jcpsilva @mail.ufv.br.

*"Médico Veterinário-Doutor-Professor Adjunto do Departamento de Veterinária da UFV - Viçosa, MG - CEP 36571-000.

**"Médico-Doutor-Professor Titular da Faculdade de Medicina da UFMG - Belo Horizonte, MG.
} 
verificar a ocorrência de eventual relação entre a existência de inflamação e de úlcera gástrica, e ainda, observar a influência da gastrite sobre a gastrinemia e sobre a densidade de alguns tipos de células endócrinas nos diferentes segmentos da mucosa gástrica.

\section{Materiais e métodos}

Foram utilizados 64 suínos mestiços, de ambos os sexos, do tipo carne, com aproximadamente cinco meses de idade e oriundos de criação intensiva pertencente à Universidade Federal de Viçosa. Após o abate desses animais, os estômagos foram separados das carcaças, abertos por meio de incisão ao longo da curvatura maior, esvaziado de seu conteúdo, cuidadosamente lavado para retirar o excesso de muco, seguindo-se de imediato o exame macroscópico da peça. Baseado na presença ou ausência de úlcera na pars oesophagea, foram divididos em dois grupos: Grupo 1- Suínos sem úlcera; Grupo 2- Suínos com úlcera.

Vários fragmentos de tecidos foram retirados ao longo da pequena e da grande curvatura, abrangendo as diferentes regiões glandulares do estômago, seguindo rigorosamente um mapeamento realizado previamente.

Após a fixação em líquido de Bouin por 24 horas, os fragmentos foram processados segundo técnicas rotineiras em histopatologia e corados pela $\mathrm{H}$-E. Cortes semiconsecutivos das mucosas oxíntica e antral foram obtidos para estudo de células argirófilas, argentafins e células $\mathrm{G}$, utilizando as técnicas de Grimelius (Grimelius, 1968), de Masson-Fontana modificada (Barbosa et al., 1984), e a imunocoloração pelo método da peroxidase-antiperoxidase (PAP) (Sternberger, 1986), respectivamente. O resultado da contagem dessas células endócrinas foi expresso em número médio de células por $\mathrm{mm}^{2}$.

O diagnóstico de gastrite cárdica, oxíntica e/ou antral foi realizado quando dois ou mais fragmentos, entre os quatro examinados em cada mucosa, apresentavam reação inflamatória. Foram considerados como portadores de gastrites os animais que apresentavam reação inflamatória simultânea em pelo menos quatro dos 12 fragmentos de mucosa glandular estudados.

De cada animal foi colhido sangue, em jejum e após estímulo alimentar, a partir do seio venoso orbital. O soro obtido, após a centrifugação, foi armazenado em freezer a $-20^{\circ} \mathrm{C}$ até a realização do radioimunoensaio. Para tal utilizou-se o Kit "Gastrin Double Antibody" da Diagnostic Products Corporation, EUA.

Para verificação da relação entre gastrite e úlcera gástrica foi utilizada a Tabela de Contingência. Para comparar o número médio de células endócrinas e os niveis séricos de gastrina em suínos com e sem gastrite, aplicou-se o teste " $t$ " de Student ao nível de significância de $5 \%(p<0,05)$.

\section{Resultados e discussão}

Dos 64 suínos examinados, 13 (20,31\%) exibiam alterações macroscópicas nas mucosas glandulares sugestivas de gastrite difusa, caracterizadas por pequenas erosões superficiais do epitélio de revestimento do estômago, mucosa de coloração avermelhada e aparente aumento de secreção de muco, enquanto os 51 (79,69\%) suínos restantes não apresentaram lesões macroscópicas dignas de nota.

A análise de 256 cortes histológicos da mucosa cárdica revelou que 98 (38,28\%) casos exibiam alterações histológicas indicativas de gastrite, em diferentes graus. Destes, 55 $(21,48 \%)$ casos pertenciam ao grupo de suínos portadores de úlcera gástrica, enquanto os $43(16,80 \%)$ casos restantes, aos suínos controles. $\mathrm{O}$ exsudato inflamatório era constituído predominantemente por células mononucleadas, sobretudo por linfócitos e plasmócitos. Os neutrófilos e os eosinófilos embora presentes, eram geralmente mais escassos. O infiltrado inflamatório se distribuía difusamente por entre as glândulas cárdicas, mas de modo mais acentuado na metade superficial da mucosa (Figura 1a). Edema, congestão e nódulos linfáticos reativos foram observados com freqüência em associação com o exsudato celular.

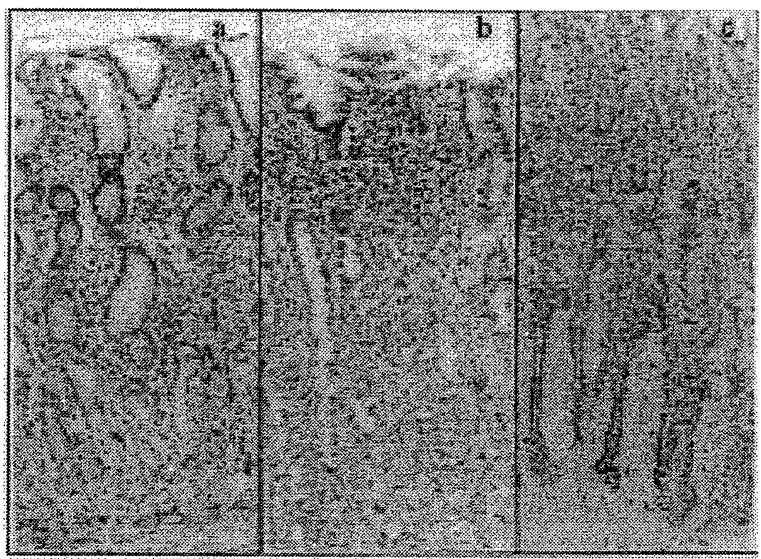

Figura 1: Processo inflamatório do estômago de suíno. Mucosa cárdica (a), mucosa oxíntica (b), e mucosa antral (c). H-E. (360X).

No exame de 256 fragmentos da mucosa oxíntica, observouse reação inflamatória em $29(11,33 \%)$ cortes histológicos. Ao grupo de suínos com úlcera correspondiam $15(5,86 \%)$ casos, enquanto os outros $14(5,46 \%)$ casos restantes, ao grupo controle. A observação microscópica da reação inflamatória na mucosa oxíntica também revelou predomínio de linfócitos e plasmócitos que se localizavam quase exclusivamente na lâmina própria subjacente ao epitélio de revestimento (Figura 1b). Os eosinófilos e os neutrófilos, quando presentes, eram encontrados nas regiões mais profundas, próximo à muscular da mucosa, onde podia ser também notado infiltrado inflamatório ocasional. No terço médio da mucosa oxintica o infiltrado de leucócitos era muito reduzido, ou mesmo inexistente. Do mesmo modo, as alterações circulatórias, quando presentes, eram bem mais discretas do que noutras regiōes glandulares do estômago.

A análise de 256 cortes histológicos da mucosa antral revelou reação inflamatória em $76(29,69 \%)$ casos. Destes, 40 $(15,62 \%)$ cortes estavam relacionados com suínos portadores de úlcera, enquanto os $36(14,06 \%)$ cortes restantes originaram-se em suínos pertencentes ao grupo controle. Como nas demais, nesta região, o processo inflamatório caracterizava-se por infiltração de células mononucleares, ora predominando plasmócitos, ora predominando linfócitos, associados à pequena infiltração de granulócitos. Este exsudato ce- 
lular se distribuía difusamente pela lâmina própria, notadamente em seu terço superior (Figura 1c). Congestão, edema e pequenos focos de hemorragias também podiam ser notados.

Pelo exposto, observa-se que as reações inflamatórias foram mais freqüentes em fragmentos de mucosa cárdica $(38,28 \%)$ e antral $(29,69 \%)$, sendo mais raros em fragmentos de mucosa oxíntica (11,33\%). Tais processos caracterizaramse por apresentar, na quase totalidade dos casos, infiltrado inflamatório predominantemente mononuclear, de intensidade discreta a moderada, sem coexistência de processos atróficos patentes da mucosa glandular. Aspectos morfológicos similares foram observados por Bertram et al. (1991) e Mendes et al. (1991). Ao contrário, em pacientes humanos os processos atróficos crônicos e as síndromes carcinóides gástricas, na maioria das vezes associadas com distúrbios da homeostase endócrina, são descritos com certa freqüência (Bordi et al., 1986; Xue-Yong et al., 1987; Cattan et al., 1989; Marotta et al., 1990; Chittajallu et al., 1992), acompanhados por exsudato celular predominantemente neutrofílico (Bertram et al., 1991).

Através de uma Tabela de Contingência verificou-se a eventual associação entre a gastrite e a úlcera gástrica. $O$ resultado desta análise nos mostra que dos suínos afetados de úlcera $(n=32), 16(50) \%$ eram portadores de gastrite, enquanto os $16(50 \%)$ restantes não apresentaram reação inflamatória na mucosa gástrica, denotando ausência de relação entre estas variáveis (Tabela 1). Este aspecto também se revela contraditório em relação à espécie humana, onde parece existir uma relação entre gastrite crônica e úlcera péptica duodenal, com a primeira precedendo a segunda. Neste contexto, por mais de uma década estudos têm demonstrado que o Helicobacter pylori é o principal agente etiológico da gastrite antral humana e, por via de conseqüência, um importante fator na patogênese da úlcera péptica duodenal (Graham, 1989). Bactérias espiraladas, semelhantes ao Helicobacter pylori, e provisoriamente denominadas Gastrospirillum suis, foram descritas na mucosa gástrica de suínos, estando associadas a processos inflamatórios locais; sobretudo a gastrite pilórica (Mendes et al., 1991). Mais recentemente, Barbosa et al. (1995) salientam que o Gastrospirillum sp. também poderia estar. relacionado a fatores possivelmente ligados à etiopatogenia da úlcera gástrica em suínos.

Tabela 1: Relação entre úlcera gástrica e gastrite em suínos

\begin{tabular}{cccc}
\hline & Sem gastrite & Com gastrite & Totais \\
\hline Sem úlcera & $23(71,88 \%)$ & $9(28,12 \%)$ & 32 \\
Com úlcera & $16(50,00 \%)$ & $16(50,00 \%)$ & 32 \\
\hline Totais & 39 & 25 & 64 \\
\hline
\end{tabular}

Procurou-se investigar ainda a eventual influência exercida pela reação inflamatória da mucosa antral sobre os niveis séricos de gastrina. Os resultados expressos na Tabela 2 mostram que naqueles animais sem evidências de reação inflamatória os niveis séricos de gastrina foram $59,61 \pm 31,75$ e $80,63 \pm 30,16 \mathrm{pg} / \mathrm{ml}$ de soro, respectivamente em condição basal e após estímulo alimentar. Já os animais portadores de gastrite no antro, os níveis séricos deste peptídeo foram $48,28 \pm 21,69$ e $80,05 \pm 34,55 \mathrm{pg} / \mathrm{ml}$ de soro, respectivamente em condição basal e após estímulo. A análise destes resultados revela que a presença de gastrite não alterou, quantitativamente, os níveis séricos de gastrina seja em condição basal, seja após estímulo alimentar. Ao contrário, Chittajallu et al. (1992) acreditam que, em pacientes humanos, a liberação excessiva de gastrina pela mucosa antral inflamada poderia ser o mecanismo pelo qual o Helicobacter pylori predispõe à úlcera duodenal.

Tabela 2: Niveis séricos de gastrina em condição basal e após estímulo alimentar $(\mathrm{pg} / \mathrm{ml})$ em suínos com e sem gastrite antral

\begin{tabular}{ccc}
\hline GrupolVariáveis & Gastrina sérica basal & Gastrina sérica pós-estímulo \\
\hline Sem gastrite & $59,61 \pm 31,75^{\mathrm{a}}$ & $80,63 \pm 30,16^{\mathrm{a}}$ \\
Com gastrite & $48,28 \pm 21,69^{\mathrm{a}}$ & $80,05 \pm 34,55^{\mathrm{a}}$ \\
\hline
\end{tabular}

Letras comparam médias entre linhas.

Foi também verificada a relação entre a presença de gastrite na mucosa antral e na mucosa oxíntica com o número de células $G$ antrais, células argirófilas do antro e células argirófilas do corpo. Os resultados contidos na Tabela 3 revelam que a densidade de células $G$ antrais foi de $110,58 \pm 60,70$ em fragmentos de mucosa desprovidos de processo inflamatório ( $n=37$ ), e de $85,64 \pm 64,23$ naqueles com infiltrado inflamatório $(n=23)$. Comportamento similar ocorreu com as células argirófilas do antro que apresentaram densidade média de $74,05 \pm 34,94$ e $70,41 \pm 24,41$, respectivamente, em fragmentos de mucosa antral sem $(n=36)$ e com reação inflamatória $(n=23)$. As células argirófilas do corpo, por sua vez, exibiram número médio de $234,23 \pm 67,23$ e $239,70 \pm 67,41$ células por campo, respectivamente nos fragmentos desprovidos de alteração inflamatória $(n=38)$ e naqueles com infiltrado inflamatório patente $(n=15)$.

A análise estatística revelou que a presença de reação inflamatória não altera, em termos numéricos, a densidade destas células endócrinas nas diferentes mucosas do estômago. Tais fatos poderiam estar relacionados com a baixa intensidade em que ocorrem os processos inflamatórios nas diferentes mucosas gástricas de suínos. Este aspecto foi também abordado por Xue-Yong et al. (1987) ao verificarem que, no homem, a gastrite antral superficial não determina decréscimo da população de células $\mathrm{G}$. Constataram, no entanto, significativa diminuição da densidade destas células em pacientes com gastrite atrófica da mucosa antral, salientando que quanto maior o grau de atrofia da mucosa, maior a diminuição do número de células produtoras de gastrina. Marotta et al. (1990) acrescentaram que tanto a densidade de células G como a concentração de gastrina da mucosa antral diminuem à medida que se aumenta a severidade da gastrite atrófica da mucosa antral. Bordi et al. (1986) verificaram hiperplasia de células argirófilas, principalmente de células Enterochromaffin-like (ECL), associada à gastrite atrófica crônica da mucosa fúndica com hipo ou acloridria. Observaram, ainda, graus variáveis de hiperplasia de células $\mathrm{G}$ na mucosa antro-pilórica de todos os pacientes estudados, o que, segundo eles, seria responsável pela hipergastrinemia. Também Cattan et al. (1989) acreditam que a hiperplasia de células argirófilas presentes em pacientes humanos com gastrite atrófica fúndica não está associada à intensidade da gastrite, mas sim aos níveis de gastrina circulante. 
Tabela 3: Número médio de células G e células argirófilas do antro em fragmentos de mucosa antral com e sem gastrite e número médio de células argirófilas do corpo em fragmentos de mucosa oxíntica com e sem processos inflamatórios

\begin{tabular}{cccc}
\hline Variáveis & Célula G & $\begin{array}{c}\text { Célula argirófila } \\
\text { do antro }\end{array}$ & $\begin{array}{c}\text { Célula argirófila } \\
\text { do corpo }\end{array}$ \\
\hline Ausência gastrite & $110,58 \pm 60,70^{\mathrm{a}}$ & $74,05 \pm 34,94^{\mathrm{a}}$ & $234,23 \pm 67,23^{\mathrm{a}}$ \\
Presença gastrite & $85,64 \pm 64,35^{\mathrm{a}}$ & $70,41 \pm 24,41^{\mathrm{a}}$ & $239,70 \pm 67,41^{\mathrm{a}}$ \\
\hline
\end{tabular}

Letras comparam médias entre linhas

Nos suínos, apesar de ter sido observado exsudato inflamatório difuso em diversas regiōes, caracterizando o quadro histológico de gastrite, em nenhum deles foi constatada a

\section{Referências bibliográficas}

BARBOSA, A. J. A., CASTRO, L. P. F., NOGUEIRA, A. M. M. F. A simple and economical modification of the Masson-Fontana method for staining melanin granules and enterochromaffin cells. Stain Technol., v. 59, p. 193-196,1984.

BARBOSA, A. J. A., SILVA, J. C. P., NOGUEIRA, A. M. M. F. et al.. Higler incidence of Gastrospirillum sp. in swine with gastric ulcer of the pars oesophagea. Vet. Pathol. v. 32, n. 2, p. 134-139, 1995.

BERTRAM, T. A., KRAKOWKA, S., MORGAN, D. R. Gastritis associated with infection by Helicobacter pylori: comparative pathology in humans and swine. Rev. Infect. Dis. v. 13, Suppl 8, p. S714-722, 1991.

BORCH, K., RENVALL, H., LIEDBERG, G. et al. Relations between circulanting gastrin and endocrine cell proliferation in the atrophic gastric fundic mucosa. Scand.J.Gastroenterol., v. 21, p. 357-363, 1986.

BORDI, C., PILATO, F., CARFAGNA, G. et al. Argyrophil cell hyperplasia of fundic mucosa in patients with chronic atrophic gastritis. Digestion, v. 35, Suppl.1, p. 130-143, 1986.

CATTAN, D., ROUCAYROL, A. M., LAUNAY, J. M. et al. Circulating gastrin, endocrine cells, histamine content and histidine decarboxylase activity in atrophic gastritis. Gastroenterology, v. 97, p. 586-596, 1989.

CHITTAJALLU, R. S., ARDILL, J.E. S.; MCCOLL, K. E. L. The degree of hypergastrinaemia induced by Helicobacter pylori is the same in duodenal ulcer patients and assymptomatic volunteers. Europ.J.Gastroenterol.\& Hepatol., v. 4, p. 49-53, 1992. presença de hipotrofia de glândulas gástricas que caracteriza a gastrite crônica atrófica, tal como ocorre em humanos.

\section{Conclusões}

Os processos inflamatórios da mucosa glandular do estômago de suínos ocorrem com freqüência decrescente na mucosa cárdica, antral e oxíntica;

Não existe associação aparente entre a ocorrência de gastrite e úlcera gástrica em suínos de terminação;

A presença de processos inflamatórios nas diferentes regiões glandulares do estômago de suíno não alterou, numericamente, a densidade de células endócrinas nestas regiōes;

A gastrinemia basal e após estímulo alimentar não foi influenciada pela presença de gastrite na mucosa antral de suínos.

CREUTZFELDT, W., STOCKMANN, F., CONLON, J. et al. Effect of short and long-term feeding of Omeprazole on rat gastric endocrine cells. Digestion, v. 35, p. 84-97, 1985.

GRAHAM, D.Y. Campylobacter pylori and peptic ulcer disease. Gastroenterology, v. 96, p. 615-625, 1989.

GRASSO, G. M., RIPABELLI, G., SAMMARCO, M. L. et al. Prevalence of Helicobacter-like organisms in porcine gastric mucosa: a study of swine slaughtered in Italy. Comp. Immunol. Microbiol. Infect. Dis., v. 19, p. 213-217, 1996.

GRIMELIUS, L. A silver nitrate stain for cells in human pancreatic islet. Acta Soc.Med.Ups., v. 73, p. 243-270, 1968.

MAROTTA, F., HAYAKAWA, K., MIKAMI, Y. et al. Relationship between gastrin cell number, serum, antral mucosa and luminal gastrin concentration and gastric acidity in antral atrophic gastritis. Gut, v. 31, p. 279-281, 1990.

MENDES, E. N., QUEIROZ, D. M. M., ROCHA, G. A. et al. Histopathological study of porcine gastric mucosa with and without a spiral bacterium (Gastrospirillum suis). J.Med.Microbiol., v. 35, p. 345-348, 1991.

RUBIN, W. Proliferation of endocrine-like (enterochromaffin) cells in atrophic gastric mucosa. Gastroenterology, v. 57, p. 641-648, 1969.

STERNBERGER, L. A. Immunocytochemistry. 3.ed. New York: Wiley, 1986.

XUE-YONG, Z., ZHONG-BING, Z., XI-TAO, C. et al. Preliminary study of the relation ship between the distribution of antral $G$ cells and the gastrin contents of the antral mucosa, gastric juice and serum in chronic atrophic gastritis. Chin.Med.J., v. 100, p. 371$376,1987$. 